\title{
Espacio, violencia y archivos en transformación: Los sensichivos en Doble de riesgo de Lola Arias
}

\author{
Space, Violence and the Archive Transformed: Sensichives in Lola \\ Arias's Doble de riesgo [Stunt Double]
}

Gail A. Bulman

Syracuse University

gabulman@syr.edu

\section{Resumen}

En los espacios interactivos de Doble de riesgo se manipula lo tangible y lo no-tangible para transformar la noción de archivo y construir récords innovadores y perdurables en los intersticios del afecto y la tecnología. Este artículo examina los registros presentados y postula que, con ellos, Arias inventa un nuevo tipo de documentación que incrusta las emociones en los eventos que las habían producido. Co-construidos por los actores y los espectadores, los sensichivos de la instalación son fluidos y transferibles. Son capaces de modificar las definiciones de comunidad y ofrecen a los espectadores herramientas para enfrentar y desmantelar la violencia.

Palabras clave: el archivo, el afecto, la comunidad, Lola Arias.

\begin{abstract}
In Argentine Lola Arias's Doble de riesgo [Stunt Double]; (2016), tangible and intangible objects are manipulated within interactive spaces to change the notion of archives and to create innovative, lasting records in the interstices between affect and technology. This article examines these new ways to document and proposes that, through them, Arias invents sensichives: archives that embed emotions into the history that produced them. Co-constructed by the artist, actors, historians, and spectators, sensichives are fluid and transferable within and among communities. In this way, sensichives have the power to transform communities and offer them unique tools to confront and dismantle violence.
\end{abstract}

Key words: archive, affect, community, Lola Arias. 


\section{Introducción}

La producción artística de la argentina Lola Arias1 se caracteriza por su interrogación de las violencias políticas y por su innovadora inclusión de voces y perspectivas afectadas por esas violencias. En sus obras tempranas la dramaturga retrata la profundidad de la violencia incrustada en nuestros sistemas sociales más básicos. Por ejemplo, en La escuálida familia (2001) se traza en forma poética el afán de abusar entre sí -física, sicológica y sexualmente-, los miembros de una familia aislada. A través de las metáforas e imágenes que se crean en la pieza, se sugiere que esta lujuria por la violencia es un rasgo fundamental del ser humano. Asimismo, en su trilogía - Striptease, Sueño con revólver y El amor es un francotirador-Arias explora las raíces de la intimidad, el amor, el poder y el miedo. Por su parte, en su producción más reciente -Mi vida después (2009) y El año en que nací (2012)-, los actores son personas que nacieron en los años del inicio de las Guerras Sucias en Argentina y Chile, respectivamente. Esas obras muestran el impacto de la violencia causada por los militares no solamente sobre las personas desaparecidas y asesinadas durante las dictaduras, sino también sobre la vida de los que apenas habían nacido.

Desafortunadamente, no hay escasez de violencia en el mundo ni de personas afectadas por ella. Por eso Arias siempre tendrá materia prima para trabajar. Sus obras, más allá de inspirar catarsis en sus participantes, destacan por la innovación estética que la artista emplea para narrar la violencia tanto global, nacional, local y personal. Distinta en cada obra, la estética de Arias es totalizante: agarra tanto a los actores como a los espectadores y muchas veces produce confusión entre los papeles de cada uno. Con su arte no sólo logra concebir obras de gran impacto artístico, sino que también logra crear nuevos tipos de archivos que graban de forma única y perdurable las violencias, a la vez que comparten sus huellas afectivas.

Entre las obras más recientes de esta artista, Doble de riesgo (2016) se aprovecha del formato de la instalación -espacio relacional e interhumano en su esencia- para transformar, entre otros, los archivos oficiales del Parque de la Memoria en Buenos Aires, así como cuestionar el concepto del archivo en general y crear nuevos archivos, innovadores y perdurables, en los intersticios entre el afecto y la tecnología. Al examinar la focalización en la obra -es decir la relación entre la posición física, sicológica y sociopolítica del espectador, con el uso y la ubicación de los objetos vistos, y el espacio de la representación- este ensayo indagará en las nuevas formas del archivo presentadas y postulará que, con Doble de riesgo, Arias crea un nuevo tipo de documentación, lo que yo denomino los sensichivos; que incorporan rasgos del

1 Fundadora del grupo teatral Compañía Postnuclear, Lola Arias es directora, dramaturga, actriz, cantante y artista visual. Para más información sobre su producción artística, ver lolaarias.com 
archivo y el repertorio, definidos por Diana Taylor; pero que también complementan y expanden estas nociones. Los sensichivos son erigidos a través de una colaboración creativa entre la artista, los actores, los espectadores y los historiadores, y se articulan como entidades vivas y fluidas, configuradas en proceso perpetuo y con la ayuda de la memoria, la historia oficial, las historias personales y el afecto. Se delinean a través de una fusión de medios - videos, fotografías, objetos tangibles, documentos, sonidos y cuerpos- y son conservados y guardados no sólo digitalmente, sino también de maneras menos tangibles e igualmente válidas y reales: en la mente de los actores, en la corporalidad de los espectadores y en el espacio compartido de la comunidad. A causa de su estructura colaborativa y su impacto abarcador, los sensichivos son capaces de transformar las definiciones de comunidad y así ayudar a renovar su acercamiento a la violencia. Grabados y guardados no solamente en las pantallas y los escenarios de la representación sino también en las plataformas electrónicas durante y después de la presencia del montaje, los sensichivos abren espacios de interacción entre la historia y la memoria, el ser y su comunidad, el artista y su público, e invitan posibilidades para empezar a desmantelar la violencia y su impacto en la humanidad. Como lo expresa Taylor "al considerar seriamente a la performance como un sistema de aprendizaje, almacenamiento y transmisor del saber, el estudio de la performance nos permite expandir lo que entendemos por el saber" (16, traducción mía). Así, los sensichivos abren camino para extender y cuestionar lo que se entiende por la violencia, la política, la historia y la noción de comunidad.

\section{La Instalación Doble de riesgo}

Los documentos son la raíz de muchas obras de Arias. Irónicamente, una de sus obras más recientes lleva este mismo título (Los documentos, 2012). Los documentos también son relevantes para Doble de riesgo, obra que resulta desafiante describir por varias razones:

1. La instalación está incrustada dentro de y al lado de los archivos oficiales -El Centro de documentación y archivo digital del Parque de la Memoria: Base de datos del Monumento a las Víctimas del Terrorismo de Estado- almacenados dentro de la Sala PaYs del Parque en Buenos Aires. ${ }^{2}$ Desde la llegada del espectador al Parque hasta su entrada en la Sala PAyS, los archivos oficiales le rodean. Por eso,

2 El Centro de Documentación y Archivo Digital consiste en una lista en orden alfabético de 8805 nombres de personas que fueron desaparecidas o asesinadas entre 1969 y 1983 y cuyos nombres se incluyen en El Monumento a las Víctimas del Terrorismo de Estado que se encuentra en El Parque de la Memoria. "La base de datos contiene información relativa a la vida y a las circunstancias de desaparición y/o asesinato de cada una de las personas inscriptas en el Monumento" (parquedelamemoria.org.ar). 
el espectador se podría "confundir" y pensar que estos archivos oficiales son parte de la obra;

2. La obra se compone de cuatro instalaciones y cada una podría ser una obra aparte, independiente; de hecho, una de ellas, "Veteranos", se estrenó como video-instalación en la exhibición "After the War" en Londres en el 2014. Por eso, lleva subtítulos en inglés (Blejmar 105).

3. Las instalaciones entremezclan medios: fotos, videos y objetos tangibles;

4. El espectador, lo quiera o no, se ve obligado a participar, aún cuando se decida no hacerlo, con el hecho de escoger cómo moverse por la instalación, cómo visitarla, qué ver o tocar. El espectador tiene toda la libertad de seleccionar el orden de su visita: Se puede empezar y terminar donde quiera, tiene la opción de no escuchar o no decir nada o de oírlo todo. Se puede saltar por encima de algunos de los videos y/o fotos o se puede tratar de ver todos.

5. Las simulaciones en cada parte juegan con el concepto del doble. Esto provoca un cuestionamiento sobre quién actúa y qué significado tiene, lo cual requiere la participación activa de los espectadores para seguir la "fábula" de la obra, aún cuando no quieran actuar. ${ }^{3}$

Al ubicar su instalación dentro del Parque de la Memoria, Arias la impregna de la historia y política de la Argentina de los últimos cuarenta años y la inscribe con el mismo marco conmemorativo y controversial del Parque, dependiendo de la perspectiva del espectador sobre el tema. Maaike Bleeker teoriza una distinción entre la perspectiva y la focalización e insiste en la capacidad de la performance de posicionar a sus espectadores y manipular lo que ven. Para Bleeker, la perspectiva finge una mirada objetiva, pura y natural. Con la perspectiva se presenta una lectura específica de lo que existe para ser mirada y se promete una imagen objetiva, fidedigna e independiente de la posición del espectador. Por otra parte, la focalización ofrece puntos de vista variables porque depende de la relación triangular entre el objeto mirado, quien lo mira y la posición o relación entre estos. La focalización depende de la relación y la posición (física, cultural y personal) del espectador con respecto al objeto visto. No obstante, aunque la perspectiva pretenda ser la manera natural y objetiva para ver e interpretar, siempre hay una jerarquización inherente a la perspectiva y esta conecta la perspectiva con las estructuras del poder. Según Bleeker, la focalización trata de romper esta jerarquización al reconocer la importancia de la posición física, política y/o cultural del espectador en la interpretación

3 Para indagar en cómo se funcionan los dobles en la obra, ver Bulman en LATR, otoño 2017, 5-26. 
del objeto visto. Es decir que la focalización crea un marco, pero el marco se transforma dependiendo de la posición del espectador.

En Doble de riesgo, hay múltiples marcos y, a pesar de la perspectiva del espectador al entrar en el Parque, estos inician el proceso de la focalización. El marco externo más obvio es el del museo del Parque de la Memoria. Al entrar en el Parque y enfrentarse con la magnitud y la solemnidad de El Monumento a las Víctimas del Terrorismo de Estado, los espectadores dejan su rutina diaria para revisitar la violencia de los años 1969-83. ${ }^{4}$ No obstante, aunque sirva inicialmente como punto de focalización externa para Doble de riesgo -dándole al espectador trasfondo y contexto para la obra de Arias- rápidamente el Parque llega a ser parte de la obra y, así, se convierte en un punto de focalización interna, difícil de separar de la obra que contiene. Como toda instalación, Doble de riesgo se fusiona y comparte rasgos de su espacio. Así, el Parque de la Memoria tiene una función dramática-estética: introduce al espectador a los temas de la obra y, simultáneamente, al convertirse en parte de esta, ayuda a cuestionar y desmantelar perspectivas preconcebidas dirigiendo la mirada a los espectadores. La inserción de la instalación dentro de este marco, sirve para reorientar las ideologías y fomentar conexiones entre los espectadores y el espacio, los actores, las historias que estos narran y los otros espectadores. Así, a través de su formato de instalación dentro de este lugar conmemorativo, se vislumbran y se priorizan las relaciones humanas y los diálogos que se tejen a causa de los fantasmas que habitan este espacio y esta obra. Nicolás Bourriaud señala que, al ser arte relacional por excelencia, el papel más importante de las instalaciones es el de fortificar y manejar los lazos interhumanos. ${ }^{5}$

Las cuatro partes de Doble de riesgo -"Veteranos", "Cadena nacional", "Ejércitos paralelos" y "El sonido de la multitud"- tienen su enfoque particular y su formato único, pero se vinculan por su temática (el impacto emocional de la historia violenta de los últimos 40 años en Argentina), por su formato (mezcla de objetos tangibles con imágenes multimedias) y por su llamada al espectador a participar. Cada una presenta los eventos políticos a través de un desahogo sicológico-afectivo por parte de un individuo.

4 La primera muralla de El Monumento lleva esta inscripción: "La nómina de este monumento comprende a las víctimas del terrorismo de estado, detenidos-desaparecidos y asesinados y a los que murieron combatiendo por los mismos ideales de justicia y equidad." Las cuatro estelas contienen los nombres y las edades de los desaparecidos desde 1969 hasta 1976.

5 Bourriaud enfatiza la "esfera interhumana" creada a través de una instalación y postula que esta aprieta, renueva, fortifica y reformula los lazos entre el artista, los objetos, el espacio, el espectador, el individuo, la comunidad, las sociedades y el mundo (1). 
Así, para entrar en más detalle sobre cada parte, la instalación "Veteranos" consiste en cinco pantallas enormes dentro de una sala oscura y se centra en el impacto emotivo de cinco ex soldados de La Guerra de las Malvinas (entre el 2 de abril y el 14 de junio de 1982). Cada pantalla se enfoca en el cuerpo de un veterano, vestido en su ropa de civil y ubicado en su lugar de trabajo actual. La sala es ruidosa y dinámica: mientras uno de los veteranos habla a todo volumen, los demás ex soldados mueven la boca, ya que tienen mucho que decir y también quieren contar su historia; por lo que es imposible entender claramente lo que dicen. El espectador puede tratar de enfocarse en una historia si decide colocarse los audífonos, pero esta acción ofuscaría las otras historias. Cada veterano se convierte en actor haciendo el papel de sí mismo, sin embargo, la obra juega con el concepto del doble, en la medida que cada actor hace varios papeles simultáneamente: actor, soldado joven reviviendo la guerra, verdadero veterano en el momento actual recordando la historia oficial y su historia personal, ciudadano argentino que vivía durante la guerra y que trata de interpretarla ahora y terapista que se auto-examina con respecto a sus acciones en la guerra y el sentido nacional de la misma.

Yuxtapuesto a la sala de los "Veteranos" se encuentra el salón largo y estrecho que alberga la "Cadena nacional". Esta instalación contiene una muestra de los eventos más traumáticos de la historia argentina de los últimos 40 años. El espacio es diseñado para imitar la oficina del presidente de la República: iluminados al final del salón hay un escritorio grande con una silla delante de unas cortinas beige. A su lado la bandera nacional. Frente al escritorio, una cámara y un teleprompter invitan al espectador a sentarse para repetir un discurso presidencial familiar o expresar sus propias ideas en su propia voz. A pesar de su subtexto violento, el salón conserva un aire sofisticado, tranquilo y elegante. Los únicos otros objetos en el espacio son nueve pantallas, cuatro en una pared, cinco en la otra. Cada pantalla revela una cara distinta y solitaria. La cara está vista de cerca y es casi inmóvil, sin expresión en sus gestos: los únicos movimientos son los de la boca que habla, pronunciando un discurso de un presidente argentino distinto en cada instancia. No obstante, la tensión entre la frialdad del pronunciamiento oral y las palabras escritas en los subtítulos que se encuentran en la parte inferior de la pantalla-palabras que revelan el impacto de ese mismo evento histórico sobre el actor-persona real que hace el papel del presidente en la pantalla- crea una ruptura entre lo que se escucha y lo que se ve y, de esta forma, abre un espacio de reflexión, interpretación y/o acción para el espectador.

Al lado del salón de la "Cadena nacional" se encuentra la instalación "Ejércitos paralelos". En el centro del cuarto hay una garita, semejante a las que se servían para proteger los vecindarios lujosos. Las garitas servían como un tipo de 
domicilio para los guardias que trabajaban o para el Estado o para compañías privadas y cuyo oficio era el de proteger a sus comunidades. Esta, lejos de estar vacía, tiene características de habitabilidad, rasgos de quienes la ocupaban, de quienes hubieran podido trabajar dentro de ellas, vigilando, llenándola de intimidad. Se puede experimentar la garita desde el exterior o desde su interior, pues se le invita al espectador a entrar en esta. En las paredes de la sala que rodean la garita, hay varias fotos. Las fotos revelan varias ópticas sobre las garitas: Una foto muestra una garita sucia con la palabra "puto" escrita en el polvo que cubre la vitrina. Otras fotos destacan otras perspectivas sobre el interior de las garitas. Se ven rollos del papel de baño, restos de comida y otras muestras de la suciedad de algunos de los lugares. Los espectadores, si deciden entrar en la garita, pueden experimentar la realidad desde ese estrecho cubículo donde trabajan los vigilantes. A través de los objetos auténticos que contiene, se captan las rutinas e intereses de los guardias que pudieran habitarla. Se huele el olor rancio a cigarrillos y se ven las sobras endurecidas de comida. También se experimenta la claustrofobia que surge como resultado del tamaño y la fragilidad del lugar.

La última parte de la exhibición, o la primera dependiendo del orden de la visita, se titula "El sonido de la multitud" y consiste en un micrófono con un equipo karaoke. Con esta escenografía sencilla pero llamativa, la artista invita a los espectadores a repetir algunos de los cantos creados por los activistas en los últimos cuarenta años o a crear uno nuevo. Se invita al espectador a cantar, gritar, proclamar declaraciones o contar historias inventadas o conocidas. La descripción de Graciela Speranza ${ }^{6}$ nos informa:

El sonido de la multitud amplifica las respuestas populares a las voces del poder en el escenario privilegiado de la participación política de las masas, en el que la memoria histórica se active por defecto. La línea de tiempo de la historia argentina moderna podría reconstruirse por entero con el inventario de consignas y cánticos que quedaron grabados en los registros sonoros de la Plaza de Mayo, ahora entreverados para que el espectador corée en un karaoke y los recomponga con su propia línea de tiempo. (en línea)

A través de sus combinaciones innovadoras de caras reales y simuladas, emociones diversas, objetos auténticos, tecnología y los cuerpos vivos de los espectadores, cada parte de Doble de riesgo crea y narra múltiples historias y nuevas miradas

6 Graciela Speranza es traductora, crítica de cine y literatura e investigadora que enseña en la Universidad Torcuato Di Tella y la Universidad de Buenos Aires. Ganó un Premio Guggenheim en el 2002. Colaboró en crear los textos para el catálogo de la exhibición. 
sobre la historia. Así, Arias manipula posibles perspectivas cerradas o circunscritas para abrirlas a otras focalizaciones. Ella amplía y maneja las perspectivas sobre estos elementos, dependiendo de qué pantalla u objeto se mira y los impulsos afectivos de cada mirada, cada momento y cada visitante. Esos impulsos afectivos, esas emociones que brotan en los intersticios entre el espacio de las instalaciones y su interacción con los humanos que se encuentran allí crean un nuevo tipo de archivo -un sensichivo- que dialoga y agrega nueva información al archivo y al repertorio.

\section{Archivo, repertorio y sensichivo}

Al ubicar Doble de riesgo dentro de los archivos oficiales, Arias manipula el enfoque del espectador para que éste se fije en los archivos, su contenido y su relación con la historia y la política de Argentina de a finales del siglo veinte y principios del veintiuno. Además de enfatizar la importancia de los archivos, la ubicación de la instalación dialoga y cuestiona el contenido y el rol de estos documentos específicos, interrogando el concepto de archivo al llamar la atención sobre las nociones de la perspectiva y la focalización, que son también fundamentales al concepto del archivo. El archivo, cuya etimología nos llega de los griegos, significa "un edificio público", "un sitio donde se guardan los récords" y se conecta con los espacios del poder (Taylor 19). Como señala Taylor, toda forma de saber -sea archivo tradicional, repertorio u otro tipo de información- se presta a la manipulación. ${ }^{7}$ Para crear un archivo, alguien tiene que seleccionar, clasificar, analizar y presentar los materiales que se incluyen allí. Por eso, el archivo tradicional incorpora la perspectiva de su archivista y es vulnerable a las fuerzas de la manipulación política y la corruptibilidad (Taylor 19).

Generalmente, cuando se piensa en un archivo, se piensa en la escritura. En su teorización del archivo y el repertorio, Taylor define el archivo tradicional y lo que ella llama repertorio. La autora articula las tensiones entre estos y afirma que estas tensiones van más allá de la dicotomía entre la escritura y la oralidad: "En un nivel, la división entre la escritura y la oralidad capta la diferencia entre el archivo y el repertorio ... Se distinguen también los requisitos de almacenamiento y diseminación. El repertorio, sea en términos de expresión verbal o no-verbal, transmite acciones vivas y corporales" (24), no obstante, ambos pueden incorporar rasgos de

7 El archivo digital del Centro de Documentación en la Sala PaYs reconoce no sólo la inevitabilidad de la mediación sino también la necesidad de la intervención para corregir y agregar información. En el sitio web se nota: "Recordamos que esta base se encuentra en constante construcción y revisión. Convocamos y solicitamos la colaboración de aquellos que puedan aportarnos información, la participación de todos es importante para mantener viva la memoria sobre los hechos ocurridos" (parquedelamemoria.org.ar). 
lo escrito y lo verbal (25). Para Taylor: "La brecha, mantengo, no se queda entre la palabra escrita y la hablada, sino entre el archivo de materiales que supuestamente perduran (ie. los textos, los documentos, los edificios, los huesos) y el así llamado repertorio, efímero, de las prácticas y los saberes corporales (ie. El lenguaje hablado, el baile, los deportes, los rituales)" (19).

Sin duda, en el siglo veintiuno, los archivos pueden tomar muchas formas. Películas, DVD, archivos sonoros y cualquier grabación digital al que se pueda acceder y guardar electrónica o técnicamente, se conceptualiza también como archivo. Lo que los define como archivos es, quizás, su intención: seleccionar y recoger cierta información, organizarla, grabarla y guardarla para su posible transferencia. Al ser una muestra tangible -sea escrito, visual, sonoro o digital- el archivo se transfiere fácilmente, de forma directa y lineal, y generalmente, sin modificaciones. Aunque el archivista tenga el poder de cambiar el contenido y la esencia de los archivos que crea, usualmente el receptor no tiene esta posibilidad. Esto sí se puede modificar -y está ocurriendo en nuestra época- con los archivos digitales interactivos, puesto que, con estos a veces el receptor sí puede agregar, modificar o corregir información con el permiso del archivista. Este es el caso de la base de datos en el Parque. No obstante, aún cuando se trate de archivos interactivos, casi siempre hay una persona o un grupo que tenga el control y que conceda acceso a la información que se incluya.

Lo que distingue al repertorio del archivo es la presencia y el impacto del cuerpo, lo que Taylor denomina embodiment, la corporalidad. El repertorio es un inventario o tesoro que permite la acción por parte del individuo o grupo y que requiere la presencia del cuerpo o de los cuerpos (Taylor 20).8 "La gente participa en la producción y la reproducción del conocimiento al 'estar presente,' al formar parte de la transmisión" (Taylor 20). La presencia del cuerpo es fundamental a lo que se considera el repertorio y por eso las prácticas performáticas tienen mucho que aportar a su teorización. Arias juega con la cuestión de la corporalidad y el concepto de la presencia física en Doble de riesgo y esto le abre espacio para crear una nueva forma de récord que va más allá del archivo y el repertorio: el sensichivo.

El sensichivo comparte rasgos del archivo tradicional y del repertorio postulados por Taylor y también desafía lo que se interpreta como la presencia y la ausencia. Taylor también teoriza otro concepto -el escenario- que permite una mirada menos

8 Taylor usa el término "repertoire" y no "repertory" para separarlo del concepto del archivo. Mientras que "repertoire" se asocia con la música, el drama y la performance, "repertory" connota "tipos de saber más archivistas: un índice, una lista, un catálogo o un calendario' y 'un almacén, una revista o un depósito, donde se puede encontrar algo.” Ver Taylor, pp. 282-83, nota 30. 
lineal que el archivo y se vuelve más abierta al incorporar ambos conceptos. Para ella, "La noción del escenario nos permite reconocer de manera más completa las diversas maneras como el archivo y el repertorio funcionan para constituir y transmitir los saberes sociales. El escenario incluye a los espectadores dentro de su marco, implicándonos en sus éticas y políticas" (33).

Doble de riesgo crea también varios escenarios y todos incluyen al espectador dentro de su marco. No obstante, lo que Arias crea, desafía los límites de lo que se puede llamar archivo, repertorio o escenario, porque lo que está más presente que nada es el afecto.

Esta obra expande dichos conceptos al crear sensichivos. Un sensichivo tiene como raíz la sensación, la sensibilidad y el sentido pero también la palabra mantiene su conexión con el archivo para enfatizar su base en los documentos reales y en su capacidad para perdurar. El sensichivo combina algún tipo de documento histórico o registro político con las emociones fuertes que el evento documentado ha producido. A través de esta combinación del archivo oficial con el afecto, como aquí en Doble de riesgo se muestra claramente, se construye un nuevo registro del evento interpretado a través de las emociones. Así, el sensichivo es un registro de una respuesta afectiva a un evento histórico que también incorpora documentación del evento, por eso el sensichivo llega a ser tan importante o quizás más importante que el evento en sí, porque es más completo. El evento permanece grabado, pero con el sensichivo es difícil separarlo de su registro afectivo. Al ser un expediente construido a través de los vestigios de los sentimientos, la sensación, el recuerdo y un archivo; el sensichivo tiene su raíz en la realidad, y no sólo en los hechos políticos e históricos, sino también en los rasgos afectivos. Por eso, el sensichivo tiene significado no sólo para el individuo que lo encarna, sino también para las comunidades a las cuales este individuo toca e incorpora.

Los únicos individuos físicamente presentes en los espacios de esta instalación son los espectadores. Las caras en las pantallas, las personas reales convertidas en actores detrás de las caras, existen y tienen una presencia a causa de las emociones que articulan y comparten, pero no tienen corporalidad en la obra. Afirmar que un ser humano ausente sigue estando presente a causa de las huellas afectivas que se producen y se emanan de su desaparición se ha convertido en un lema de la identidad argentina desde la Guerra Sucia: “¡Aquí Presente!”; “¡40 Años Presentes!”. Con su manejo estético, que una vez más desaparece al cuerpo y llena el espacio con el afecto, Arias muestra cómo los afectos se apropian del contexto e infectan a los únicos cuerpos físicamente presentes: los de los espectadores. Al hacer vivir y encarnar las emociones, Doble de riesgo participa en su transferencia a otros cuerpos 
y construye una concientización comunitaria. A través de la priorización y presentación de los afectos, se vislumbra un lazo entre los seres humanos, tanto los presentes como los ausentes, con respecto a la historia y el momento actual. De esta forma, se da cuenta de que la violencia histórica les ha marcado y les sigue impactando a todos. Aunque las emociones que brotan sean distintas, hay emociones que impactan tanto al individuo como a su comunidad.

\section{E1 sensichivo en la práctica}

Doble de riesgo muestra cómo se puede apropiar de los archivos e invertir jerarquías a través de la creación de sensichivos, los cuales son más fieles a la historia, las historias, la memoria y el afecto. Cada parte de la instalación incorpora archivos tradicionales de varias formas y, al mismo tiempo, depende del repertorio -cuerpos presentes- y de elementos más efímeros -recuerdos y afectos- por su esencia. En "Cadena nacional" el sillón de Rivadavia, artefacto histórico en sí, es el trasfondo de la acción. ${ }^{9}$ En las paredes, cada pantalla presenta una sola cara pronunciando un discurso presidencial distinto, enunciado dentro de los últimos 40 años: El "Primer discurso como presidente de facto" (Jorge Rafael Videla, 30 de marzo de 1976), el fin de la Guerra de las Malvinas (Leopoldo Fortunato Galtieri, 15 de junio de 1982), la víspera de las elecciones democráticas (Reynaldo Benito Antonio Bignone, 29 de octubre de 1983), los problemas económicos y políticos que impiden el "buen” gobierno (Raúl Alfonsín, 29 de mayo de 1989), la eliminación de las regulaciones (Carlos Saúl Menem, 1 de noviembre de 1991), El “decreto de estado de sitio" (Fernando de la Rúa, 19 de diciembre de 2001), la desaparición de Luis Gérez (Néstor Kirchner, 29 de diciembre de 2006), la muerte de su esposo (Cristina Fernández de Kirchner, 1 de noviembre de 2010), y el discurso de asunción (Mauricio Macri, 12 de octubre de 2015). Aunque lo único que se escucha al colocarse los audífonos son los discursos presidenciales, todas las pantallas también captan otra historia: la del impacto de este pronunciamiento sobre la persona cuya cara se ve en la pantalla, es decir, la persona real aquí convertida en actor. Esta otra historia se escribe en los subtítulos que se desplazan en la parte inferior de la pantalla y por eso es más visible y accesible al espectador.

Asimismo, las tensiones son varias. La más obvia se encuentra en la ironía del pronunciamiento frío del discurso político expresado por una persona cuya vida se alteró en forma negativa por ese mismo discurso. Los ojos que le clavan al espectador, junto con los subtítulos en la parte inferior de cada pantalla, expresan el trauma

9 Bernadino Rivadavia (1780-1845) era el primer presidente de la república argentina. Julieta Grosso afirma que el sillón de la instalación es de Rivadavia. 
que estos seres han sufrido a causa del pronunciamiento expresado. Los traumas que se articulan son múltiples: entre estos, el padre de Mariano Speratti desapareció cuando Mariano tenía tres años, Gabriel Sagastume fue herido y vio la muerte de muchos de sus amigos en la Guerra de las Malvinas, Martín Galli fue herido con un disparo por la policía cuando participó en una protesta callejera. ${ }^{10}$ También hay tensión entre las nueve pantallas y los objetos reales que se aíslan al final de la sala, tratando de simular la oficina del presidente y de copiar-recrear el escenario en el que se pronuncia un discurso importante en la cadena nacional. Así también, un letrero invita al espectador convertirse en actor al sentarse frente al escritorio y expresar su propio discurso en el teleprompter. A su vez, se puede percibir cómo las pantallas compiten entre ellas cuando nueve caras diferentes se enfrentan y le hablan al espectador a la vez. Y, además, dentro de cada pantalla el doble se multiplica puesto que los actores son más de dos personas: son y no son el presidente, son y no son ellos mismos, son y no son actores, son y no son otro.

Además, cabe destacar que la instalación "Cadena Nacional”, compuesta por transcripciones de los discursos más impactantes de los últimos nueve presidentes de la República Argentina fue construida en y para el museo. De esta forma, se vuelve parte o extensión de los archivos oficiales y comparte muchos rasgos de estos. Física y literalmente, la instalación reemplazó los archivos originales y se tuvieron que mover temporalmente a una pequeña sala al lado para que Doble de riesgo se pudiera apropiar del espacio más grande de la Sala PaYs. Para el espectador, es difícil reconocer el límite entre los archivos oficiales y la obra de arte.

Cada sección de Doble de riesgo es única en su perspectiva y su presentación, sin embargo, en todas hay una combinación creadora de documentos y elementos oficiales, afectos en proceso sumado a los cuerpos presentes de los espectadores.

Por otro lado, en "Veteranos", las imágenes visuales que se presentan son sin rupturas y fluyen suavemente. Hay un sólo cuerpo en cada pantalla -el del veterano- y hay muy poca acción. ${ }^{11}$ A pesar de esto, hay movimiento por las rupturas afectivas, por lo tanto, cuando hay acción, esta es inspirada por las fuertes emociones evocadas. Cada veterano es como un camaleón metamorfoseándose sicológicamente frente al espectador, a través de las múltiples emociones contradictorias y vacilantes que se destapan.

10 Los otros actores son: Sebastián Soler, Javier Swedzky, Denise Goesman, Rubén López, Elvira Oneto y Helena Goldstein. Estos también experimentaron dificultades económicas, políticas o personales y en muchos de los casos estas fueron causadas por el pronunciamiento que se articula aquí.

11 En el video del sicólogo, entra también uno de sus clientes para mostrarlo dentro de su entorno profesional. 
Los archivos tradicionales que forman la base de esta instalación son registros históricos de la breve, pero impactante Guerra de las Malvinas. Aunque duró sólo setenta y cuatro días, la Guerra de las Malvinas desenmascaró el fracaso, la decepción y los actos abusivos y criminales del gobierno argentino. ${ }^{12}$ En cada pantalla, al mismo tiempo que el veterano indaga en la historia de su país y las decisiones de sus líderes, se cuestiona a sí mismo con respecto a su papel en esa guerra y sus acciones pasadas y presentes: ¿Por qué le tocó luchar en esa guerra sin sentido? ¿Cómo pudo haberse convertido en asesino? ¿Cómo ha podido sobrevivir cuando algunos de sus amigos se murieron? ¿Pudo haber hecho algo para salvar a sus amigos? ¿Qué significó/significa la Guerra de las Malvinas para su patria? Las palabras de cada veterano - tanto las subtituladas como las dichas- se presentan de manera fragmentada y develan las acciones exteriores y la perturbación interior del protagonista. Es así como la fragmentación refleja el impacto afectivo de la violencia que sufrieron los soldados y el hecho de que siguen sufriendo tanto los veteranos como los ciudadanos civiles.

Para el espectador, las historias que los veteranos despliegan son igual de fragmentadas por varias razones: cinco historias distintas se proclaman visual y verbalmente en cinco pantallas que engloban recuerdos del pasado, reacciones en el presente, historias personales y la historia nacional. La manera en que Arias construye la representación hace que el espectador entre en este mundo fragmentado para tratar de descifrarlo. También, fuerza al espectador a tratar de recomponer la historia y componer sus propias interpretaciones y vivencias personales, al juntar algunos de los fragmentos. Como es imposible captarlos todos, por su cantidad, diversidad y la configuración del montaje, el espectador tiene que reflexionar sobre lo que él mismo entiende por la historia y por su propia experiencia para hacer comparaciones y cuestionamientos. Así, se transfiere el sensichivo presentado en cada pantalla y se empieza a ampliar y expandir, dejando espacio para otros afectos y diversas lecturas.

Por su parte, "Ejércitos paralelos" incorpora documentos, imágenes y objetos banales que se vuelven parte de los archivos tradicionales que documentan la vida

12 Jonathan C. Brown afirma que la derrota que los argentinos sufrieron a manos de los ingleses en la Guerra de las Malvinas les dejó atónitos y luego furiosos: "De repente, se dieron cuenta de que las fuerzas armadas habían sido eficaces en desaparecer a sus propios ciudadanos, en disimular su propia corrupción y sus abusos de los derechos humanos, en destruir el poder de los peronistas, en intimidar la inteligencia, en robar la porción más grande del presupuesto nacional, y en gastar las ganancias de los préstamos internacionales considerables, pero que no podían realizar su misión constitucional de defender a la patria” (Brown 252). 
profesional y personal de quienes sirvieron de guardias. La garita en sí, sin los otros artefactos que se incluyen en la instalación, es una metáfora que reemplaza al ser humano que generalmente la habita. También, resulta relevante que las garitas son espacios privados y cerrados, reservados para los que dominan. Tres detalles amplían esta garita y la instalación "Ejércitos paralelos", convirtiéndolas en sensichivos. Primero, el hecho de que esta garita se abra a una invasión pública, carente de su dueño, transfiere el poder de este espacio al pueblo. Ya no es espacio privado, zona prohibida y, por eso, se destapa el misterio "natural" del lugar. Cuando se invita al espectador a entrar en la garita y ver el mundo a través de los ojos de quienes tienen el "poder", le permite ver el mundo desde otras perspectivas y cuestionarse con respecto al rol de la garita y los guardias que los "protegían": ¿A quién se va a proteger desde este cubículo frágil? ¿Se trata de la protección o de la vigilancia y la observación?

Por último, "Ejércitos paralelos" se destaca por la ausencia del guardia. Se ve su "casa", se escucha su voz (a través de una grabación auditiva que se oye en la sala) y se ven fotos de su mundo, pero el guardia no está presente, es el espectador quien lo reemplaza. Nuevamente, los únicos cuerpos presentes son los de los espectadores, ¿será un momento de concientización para el espectador cuando se dé cuenta de que la única persona quien realmente le puede proteger es él mismo? Así, esta vez, son los policías y los poderosos -los guardias- quienes han desaparecido y son físicamente reemplazados por el pueblo: el espectador que ve la instalación y que pueda cruzar libremente el umbral de la garita. En "Ejércitos paralelos" la ausencia del guardia, aún cuando tantos detalles de su vida estén presentes, colma al espectador de recuerdos y afectos, provocando cierta concientización sobre la fragilidad de la seguridad y lo efímero del poder. Al mismo tiempo, se exhuma el miedo del espectador con respecto a la seguridad y le invoca la necesidad de protegerse a sí mismo.

Finalmente, "El sonido de la multitud" se centra por completo en la participación del espectador. Para crear esta instalación, Arias hizo una llamada al pueblo a través de Facebook y otras redes sociales, y así creó los archivos históricos que formaron la plétora de cantos, palabras y eslóganes que los espectadores pueden escuchar, repetir y/o pronunciar en el micrófono. Esos cantos imitan muchos de los que se han articulado durante las numerosas protestas que se llevaron a cabo (y siguen teniendo lugar) en la Plaza de Mayo, frente al Palacio Rosado del Presidente de la República. Pero, al igual que en las otras secciones de Doble de riesgo, los únicos cuerpos presentes son los de los espectadores. Por eso, si hay un repertorio creado en "El sonido de la Multitud" será a través de la corporalidad del espectador. 
No obstante, más que archivo o repertorio, con esta sección Arias también crea, guarda y transfiere sensichivos. Los cantos escuchados por los espectadores están llenos de emociones diversas y la única manera de "ver" la instalación es participando en ella: tomando el micrófono y hablando. El espectador tiene varias opciones. Entre estas, puede sólo leer las palabras en la pantalla karaoke y repetir las de otro. O, por otra parte, el espectador puede expresar sus propias emociones y su propia pasión, inventar un discurso o crear cantos o eslóganes basados en su propia experiencia. No importa qué opción el espectador escoja, el sensichivo se graba. Se ha guardado horas de estas performances hechas por el público. Estos nuevos sensichivos se compartieron con el público presente en la instalación, pero también, estas grabaciones en mp3, estos nuevos expedientes sonoros digitales, seguirán existiendo: se pueden publicar en Facebook, YouTube u otros sitios electrónicos; o se pueden guardar en el Parque o en otros museos, como si fueran archivos oficiales. Sin embargo, no son oficiales estos nuevos sensichivos porque, además de hacer visibles los eventos históricos, proveen un registro afectivo vigente que los marca.

\section{La preservación y la transferencia del sensicbivo: Los dobles de riesgo en la comunidad}

Si los archivos tradicionales, generalmente, se basan en documentos escritos, la ironía de Doble de riesgo es que toma los documentos escritos originales y los vuelve más efímeros que las emociones, porque en la obra los documentos se convierten en expresiones orales pronunciadas por los actores, mientras que las emociones son lo que está escrito (como subtítulos) e inscrito (en las caras de las pantallas). En la obra el registro más enfatizado es el afectivo, porque es documentado visualmente, y, como el archivo y el repertorio, estos sensichivos también se guardan de muchas maneras y tienen la capacidad de transferirse.

Hay dos maneras tangibles en que los sensichivos se comparten. Por un lado, lo tangible (los escenarios de la representación, las pantallas, la garita, las fotos, la utilería y el equipo karaoke) contienen registros de los sensichivos y estos se exhiben durante y después de la presencia del montaje. Estos objetos físicos forman registros perdurables que han guardado los documentos junto a los afectos que esta documentación ha inspirado. Por otro lado, Arias - en colaboración con sus espectadores- crea un segundo tipo de expediente tangible al hacerles participar y estar presentes. La directora invita a los espectadores a involucrarse en la creación de nuevos sensichivos y muchos han aceptado su invitación. Algunos han documentado sus reacciones afectivas frente a la cámara o en el micrófono y estos han concebido nuevos sensichivos que se pueden transferir también. Arias ha confirmado que se han grabado muchas horas de los discursos de los espectadores. Cuando se digitalicen 
las voces de los espectadores, archivos de sus propios afectos, reacciones y experiencias, estos también se pueden guardar de varias formas tangibles: en un sitio web, en una red social, en este u otro museo o en sus celulares personales.

Junto a estos dos registros tangibles -el original de la representación y el nuevo que emerge por la participación del espectador- el sensichivo se puede grabar y se transferir, también, de manera menos tangible. Para el espectador estos records se extienden y se transfieren a él porque su cuerpo -el único cuerpo presente- se contagia de estos nuevos conocimientos que contiene la documentación mezclada de los afectos producidos por esta información. Además, al ver y oír los sensichivos, el espectador tiene que comprometerse con estos de una forma u otra. No hay más remedio en Doble de riesgo porque nada es circunscrito o interpretado. Por eso, cada espectador se contamina de los nuevos conocimientos que emergen de los sensichivos y es obligado -a través del montaje construido por Arias- a hacer algo. En esta necesidad de comprometerse no sólo con la historia sino con el impacto emocional de la historia, el espectador, al ser el único cuerpo presente, se convierte en el doble de riesgo.

Cristina Civale define el doble de riesgo como "una persona que, generalmente en cine, preparada para escenas de acción toma el lugar del actor-actriz que encarna un personaje para llevar adelante despliegues que encierran peligro y que el actor-actriz no está capacitado para hacer: peleas, saltos al vacío . . ." (Página 12). Por su contacto con los sensichivos y la expansión obligatoria de estos, a través del montaje que Arias construye, los espectadores se transforman en los dobles de riesgo. Al ser los únicos presentes, contagiados por los afectos instigados por la historia y obligados a actuar de alguna forma, los espectadores vuelven a su vida "normal" y vuelven a sus comunidades impregnados de estos nuevos saberes. Armados de estos saberes e impactados por estos nuevos registros históricos-afectivos, son obligados a actuar en el lugar de sus compañeros ausentes para confrontar la historia y enfrentar las violencias postuladas por esta. De este modo, la noción de comunidad se transforma. Ya no es una comunidad jerarquizada y dócil, sino una comunidad que se asemeja más a la definición de comunidad postulada por Jacques Rancière, es decir, una comunidad de individuos que "están unidos al tiempo que separados," su idea de "being together, being apart" basada en la idea del disenso, para Rancière la comunidad no es un grupo cohesivo en donde todos los miembros piensan, se sienten y actúan lo mismo, sino un pueblo en donde, a pesar de tener una diversidad de ópticas, experiencias y emociones, todos los miembros son iguales en su singularidad.13 Al esforzar a los espectadores a estar presentes y

13 Rancière afirma: «El poder común a los espectadores no reside en su calidad de miembros de un 
hacer algo con las emociones también presentes, Arias crea una comunidad al estilo de Rancière. Emancipa a sus espectadores y les exige a convertirse en ciudadanos activos y presentes, armados y empoderados de nuevos saberes. El espectador de Doble de riesgo es testigo de un sinnúmero de emociones fuertes detrás de las caras vacías de los sensichivos. La obra le urge al espectador a hacer algo frente a estos nuevos “documentos". Sin embargo, la obra no le pide al espectador compartir el mismo sentimiento ni imitar la emoción de ninguno. La estructura de la obra impide esta posibilidad por la competencia que se crea entre el número de pantallas, la multiplicidad de dobles detrás de las distintas caras (presidente-actor-persona real) y los varios discursos (del presidente y del desahogo emocional del actor-víctima de la violencia) que incluye. El espectador responde, bajo sus propios parámetros, a un llamado a participar por parte de la directora. Pero al ser bombardeado debido a tantas emociones provocadas por una plétora de eventos violentos y dañinos, el espectador tiene dificultad en conectarse con una sola historia o un sólo evento o con una emoción específica. Lo que sí se destaca es la prioridad de las emociones al leer e interpretar y posteriormente guardar el recuerdo del evento. El espectador experimenta los sensichivos y, porque tiene que actuar de alguna manera, también se convierte en un vehículo para su transferencia.

Los sensichivos abren espacios de interacción entre la historia y la memoria, el ser y su comunidad, el artista y su público, y da cuenta de nuevas posibilidades para empezar a desmantelar la violencia y su impacto afectivo. Bleeker postula que la performance es una manera de desarmar una perspectiva fija y estancada y de plantear nuevas ópticas más abarcadoras e innovadoras a través de la focalización. Los sensichivos de Doble de riesgo no sólo complementan los archivos oficiales de la base de datos, sino que también se revelan como "documentos" aún más necesarios y útiles porque están basados en las emociones, las cuales están más presentes en el momento actual que el mismo evento que las había inspirado. Siempre se puede olvidar el evento, aún cuando esté documentado. Pero el sensichivo no se olvida porque incorpora el evento y lo interpreta afectivamente. El sensichivo se guarda, se modifica y se comparte, pero nunca se borra. El montaje creado por Arias permite su transmisión, su documentación y su alteración, pero nunca su desaparición.

cuerpo colectivo o en alguna forma específica de interactividad. Es el poder que tiene cada uno o cada una de traducir a su manera aquello que él o ella percibe, de ligarlo a la aventura intelectual singular que los vuelve semejantes a cualquier otro aun cuando esa aventura no se parece a ninguna otra. Ese poder común de la igualdad de las inteligencias liga individuos, les hace intercambiar sus aventuras intelectuales, aun cuando los mantiene separados los unos de los otros, igualmente capaces de utilizar el poder de todos para trazar su propio camino" (23). 
Expedientes complejos que se constituyen de redes verbales y visuales, los sensichivos creados dependen de "los actos de transferencia" para su existencia. Con su priorización en grabar el afecto y yuxtaponerlo a los documentos oficiales, y su insistencia en una participación activa con respecto a estos, Doble de riesgo y sus participantes construyen sensichivos que comparten nuevos saberes y reinventan comunidades donde el afecto forma una parte esencial de lo que se entiende por archivo. En un mundo que carece de sensibilidad, a través de sus sensichivos, Arias privilegia el espacio afectivo para recordarnos que un evento político o histórico sólo importa por el impacto que tiene sobre los seres humanos. Una vez que se reconozca esto, podemos convertirnos en los dobles que están presentes para tomar el riesgo de actuar con la sensibilidad necesaria para salvar nuestra humanidad. 


\section{Obras citadas}

Arias, Lola. Doble de riesgo. 10 Agosto - 13 noviembre 2016, Parque de la Memoria, Buenos Aires.

_. La escuálida familia. Centro Cultural Ricardo Rojas, 2001.

_. Mi vida después y otros textos. Reservoir Books, 2016.

_.. Trilogía: Striptease, Sueño con revólver, El amor es un francotirador. Entropía, 2007.

. Mis documentos. http://lolaarias.com/proyectos/mis-documentos-2/. Visitado el 22 agosto 2017.

Bleeker, Maaike. Visuality in the Theatre: The Locus of Looking. Londres: Palgrave Macmillan, 2008.

Blejmar, Jordana. "Autofictions of Postwar: Fostering Empathy in Lola Arias' inefield/Campo minado." Latin American Theatre Review. Vol. 50, no. 2 (2017): 103-23.

Bourriaud, Nicolas. Post-production: Culture as Screenplay; How Art Reprograms the World. Lukas and Sternberg (2002).

Brown, Jonathan C. A Brief History of Argentina. Lexington Associates, 2010.

Bulman, Gail. “Not My Choice: Feeling as a 'Productive Paradox' in Lola Arias's Doble de riesgo" Latin American Theatre Review. Vol. 51, no. 1 (2017): 5-26.

Civale, Cristina. "Esta boca es suya." Página 12, http:/ / cristinacivale.net/lola-ariasesta-boca-suya/ 19 agosto 2016. Visitado el 23 septiembre 2017.

Grosso, Julieta. "Lola Arias y una muestra sobre los tiempos de la Guerra de Malvinas y del presente en el Parque de la Memoria." Télam. http://www.telam.com.ar/ notas/201608/158538-malvinas-muestra-lola-arias-parque-de-la-memoria.php 10 agosto 2016. Visitado el 23 septiembre 2017.

Parque de la Memoria página oficial. http://parquedelamemoria.org.ar/sobre-elparque-de-la-memoria/ Visitado el 11 agosto 2017.

Rancière, Jacques. El espectador emancipado, traducido por Ariel Dilon. Buenos Aires: Bordes Manantial, 2008.

Speranza, Graciela. Doble de Riesgo. Lola Arias, https://lolaarias.com/es/stuntdouble/ 
TEATRO RECIENTE EN CHILE Y ARGENTINA: DOCUMENTO, VIOLENCIA Y POLÍTICA

Taylor, Diana. The Archive and the Repertoire: Performing Cultural Memory in the Americas. Duke University Press, 2003.

Veronese, Daniel. BAiT: Buenos Aires in Translation: Four Plays from Argentina. Ed. Jean Graham-Jones. Minneapolis: Martin E. Segal Theatre Center, 2008. 